\title{
Integrating Mental Health Professionals in Residencies to Reduce Health Disparities*
}

\author{
Emilee Delbridge, $\mathrm{PhD}$ \\ Indiana University Purdue University-Indianapolis \\ Max Zubatsky, PhD \\ Saint Louis University \\ Jocelyn Fowler, MS \\ Saint Louis University
}

*The authors presented a workshop containing similar material at the $37^{\text {th }}$ Forum for Behavioral Science in Family Medicine, September 21-24, 2016 in Chicago, IL.

This is the author's manuscript of the article published in final edited form as:

Delbridge, E., Zubatsky, M., \& Fowler, J. (2017). Integrating mental health professionals in residencies to reduce health disparities. The International Journal of Psychiatry in Medicine, 52(3), 286-297. 


\begin{abstract}
The healthcare disparities of patients in primary care centers are a concern for practitioners as well as patients. One of the approaches to addressing the biopsychosocial concerns of patients is to integrate mental health providers_including mental health students-into primary care clinics. This article addresses the current literature for including mental health learners and licensed providers into family medicine residency training clinics. Descriptions of these models at two different Family Medicine residency clinics in the Midwest United States are provided. Examples of training both medical residents and mental health students are described. The integrated models described are effective in treating patients who have limited income and have various medical comorbidities with depression. Challenges to effective integration are discussed, including larger system buy-in, medical providers’ knowledge of mental health treatment, and the skills that providers in the clinic possess regarding their presentation of mental health options to patients. The development of treatment and collaborative skills by medical providers, mental health clinicians, and auxiliary providers is another challenge discussed.
\end{abstract}

(Int'l. J. Psychiatry in Medicine 2017; 00:000-000).

Key Words: biopsychosocial model, collaborative care, medical family therapy, primary care behavioral health, health disparities 


\section{BACKGROUND}

Patients who receive healthcare services at clinics that train medical trainees and mental health trainees frequently have multiple medical diagnoses, as well as co-morbid mental health concerns. Mental health disorders have been identified as affecting approximately $10 \%$ of the global population [1]. Therefore, learners in these clinical contexts have opportunities to learn how to treat complex and co-morbid diagnoses. Opportunities exist for medical and mental health trainers and learners to collaborate to improve the health of patients in these treatment settings. Some authors have suggested that providing integrated mental health care in primary care settings improves patient health outcomes and reduces costs [2-4]. These and other authors have also highlighted the need for training for providers in integrated care, as well as further research demonstrating the impact of implemented integrated care.

\section{THE BIOPSYCHOSOCIAL MODEL}

Traditionally, family medicine residents and trainees have been encouraged to work from a biopsychosocial model of care [5-6]. Engel’s framework views a holistic view of the health of patients, where the determinants of disease go beyond just the physiological complications of disease. As physicians and primary care providers continue to address psychosocial issues in their routine care of patients, the importance assessing for underlying risk factors and areas in the health of patients is critical. Given the briefness of appointments, chronicity of presenting problems and lack of mental health coordination in some primary care clinics, attending to all aspects of disease becomes challenging for many providers.

To address many of these underlying issues in patients' lives, behavioral health consultants (BHCs) have had increased roles in primary care and residency education [7]. Medical family therapists (MedFTs) are mental health therapists who have training in both the 
psychosocial aspects of mental health, attend to the social and community determinants of health, and also address the mental health concerns that are often comorbid with biomedical diagnoses [8]. These professionals learn to work with medical professionals and on interdisciplinary teams to provide comprehensive care for a variety of medical issues, including asthma [9], diabetes [10], chronic pain [11], and smoking cessation [12]. Additionally, MedFTs have emerged to provide secondary roles in medical settings, including behavioral health coaches, brief interventionist, patient advocates, and faculty who train medical professionals and residents [13].

\section{INTEGRATING BEHAVIORAL HEALTH IN PRIMARY CARE}

Integrated care has been defined as comprehensive, patient-centered care that is delivered as personalized, humanistic treatment. This treatment is often be provided by a team of healthcare professionals who work collaboratively [4]. These settings may also include both supervisors/faculty and trainees, which add another layer of collaboration. Collaborative care has been defined as "an approach in which primary care and mental health providers collaborate in an organized way to manage common mental disorders” [14]. Generally, treatment is problemfocused, with one or two, specific and measurable treatment goals identified; therefore, treatment is also brief, lasting less than ten sessions, on average [15]. In the settings in which the authors practice and teach, both medical learners (primarily, family medicine residents) and family therapy learners collaborate and receive training. The faculty members emphasize different learning outcomes with different sets of learner-practitioners. The literature on training mental health learners and practitioners to work within primary care and other medical settings has been discussed above and in other publications. However, few studies or publications exist regarding training medical learners or practitioners the knowledge, skills, and attitudes of collaboratively 
working with mental health providers. Within the field of interprofessional education and practice, researchers and practitioners have started to specify skills for different healthcare practitioners to develop and utilize in order to address mental health concerns of patients [16]. Specific learning and practice examples of integrating BHCs into primary care will be detailed below.

\section{ACTIVITIES}

\section{INTEGREATED BEHAVIORAL HEALTH CONSULTANTS IN FAMILY MEDICINE}

At Saint Louis University, the MedFT program faculty members train students who provide therapy in primary care settings, working with residents in the Department of Family and Community Medicine. The graduate degree and residency programs are located in the Midwest, with 18 family medicine residents and 18 graduate students who participate in both clinical care and educational activities together. Master's and doctoral students provide clinical services in four primary care clinics in the St. Louis area, serving multiple roles in both patient care and resident training. Students are trained and supervised to provide brief consultations and participate in team meetings with patients and families around complex medical and family issues.

At one of these clinics, a MedFT clinician and other BHCs provide a number of roles at a Federally Qualified Health Center (FQHC). The MedFT is integrated in a primary care behavioral health model, offering consultations, brief screenings, assessments, and coaching to chronically ill and patients who are high utilizers of healthcare services. The MedFT also helps with continuity of care transitions after a patient's discharge from the hospital. Both the MedFT and residents work together to streamline patients' care into the FQHC, identifying resources and 
social support services to prevent further complications upon discharge. The goal is for the patient to receive comprehensive services upon discharge and for the team to identify barriers or risk factors early in this transition process. The case example provides a brief description of services offered by a student at the FQHC clinic (Appendix A).

\section{PRIMARY CARE BEHAVIORAL HEALTH TEAM}

The key members of the primary care behavioral health team are a medical provider, the mental health provider, and the patient. Within integrated care settings, the person who takes the lead in the management of the team varies depending on the specific context, needs, and situation. If a patient has a number of complex, co-morbid medical and mental health diagnoses, then the physician may well take the lead in planning the care, with the mental health provider seeing the patient either during the same medical visit or less frequently. If the main concerns are related to mental health—such as coping with diagnoses, developing effective communication skills to use with family members, and practicing anxiety management skills — then the mental health provider/MedFT may take the lead on the team by setting specific treatment goals and scheduling regular appointments. If the patient is highly motivated, is not experiencing any acute or risk symptoms, and has identified the goals for their care, the patient may function as the leader of the team. Certainly, there are a number of other members of the team, such as nursing staff, scheduling personnel, specialty medical health providers, and billing administrators who all play roles in the care of a patient.

The Indiana University (IU) Family Medicine Residency is located in the Midwest United States, and the Indianapolis metropolitan area has a population of 1.7 million people. The Residency has 39 residents. The Residency Clinic serves 12,000 newborn to geriatric patients. 
At the clinic at the IU Family Medicine Residency, the physician is generally the person to suggest and explain to the patient about the counseling services available. If possible, a family therapist meets the patient in order to establish a connection—often called the warm hand-off. Another option for referring a patient is for the patient to fill out a form whose goal is for the patient identify the goal for counseling, as well as to rate his/her levels of importance and confidence in reaching that goal [17]. The patient then is scheduled for a 40-minute triage appointment with a family medicine resident-Behavioral Science faculty team to determine if the patient is a good fit for short-term counseling at the clinic, or if the patient's needs would be better served at a specific community mental health clinic that has more services available, including psychiatric treatment options. The treatment recommendations are communicated to the patient, the patient's primary care provider, and the provider who referred the patient for counseling initially.

\section{OUTCOMES}

Reducing the health disparities for patients in primary care settings is the goal for both medical and mental health providers. We have discussed models of practice and training, including literature and approaches from other researchers and practitioners. The next sections will focus on preliminary outcomes at our training sites.

\section{APPROACHES TO TEACHING AND TRAINING}

Though our underlying goal is to address the health needs of patients, there are concurrent goals, as well. Since the residents who practice at the IU Family Medicine Clinic all have the ability to refer patients to BHCs at the clinic, a pilot study was conducted in order to understand how these medical residents had utilized the integrated mental health services at the 
clinic. The majority of residents had referred patients to the mental health services (Table 2). Of those residents who had referred patients, almost three-quarters had recalled receiving follow-up communication from the mental health provider. Sixty-five percent of residents had stated that their patients had made some improvement. No respondents reported any worsening symptoms or new concerns. Continuing to monitor medical residents’ perspectives and experiences in training in a clinic with integrated BHCs is an important aspect to training primary care providers and identifying approaches that result in improved mental and physical health outcomes for patients, especially individuals in vulnerable populations.

\section{PRACTICE PATTERNS OF MFTS TREATING HEALTH DISPARITIES}

Data was collected from MedFTs who provided services at three primary care clinics from June 2012 to June 2015 (Table 2). MedFTs were Master’s and doctoral students who completed several courses and training prior to their integration in these clinics. A total of 334 patients were seen by MedFTs during this time period. In order for patients’ data to be included in the study, MedFTs had to see the patients for at least one documented appointment. Demographic and practice data was extracted from electronic medical records at these sites. $^{1}$

Overall, MedFTs treated nearly 25\% of patients who self-identified as a racial minority with chronic health issues, mostly African American patients. Regarding socioeconomic status (SES), 31.6\% of patients seen by MedFTs were either “lowest or lower middle SES.” The most prevalent comorbidities with depression in patients were obesity (25.2\%), arthritis (18.9\%), and musculoskeletal pain (17.4\%). The top ten most prevalent chronic health issues co-occurring with depression were present in at least 5\% of the patients seen by MedFTs.

\footnotetext{
${ }^{1}$ This study received approval from the Institutional Review Board at Saint Louis University.
} 


\section{FUTURE DIRECTIONS}

\section{CURRICULUM FOR BEHAVIORAL HEALTH CONSULTANTS}

Training programs for mental health professionals working in integrated care settings could benefit from implementing health disparities curriculum. Clinical supervisors could focus training students to recognize and address the intersections of physical health and mental health; examples of appropriate presentations include disease prevention [18], childhood health concerns [19], and patients' access to care [20]. As MedFTs continue to develop core competencies for working in healthcare and medical settings [21, 22], more comprehensive curricula in marriage and family therapy, psychology, and social work programs can be developed and standardized. Consistent, routine evaluations of students by program faculty members ensure that learners possess the required skills and attitudes that are expected of BHCs in integrated care. As more emerging professionals continue to assume training and career positions in primary-, secondary-, and tertiary-care settings, [23] programs may consider developing more clinical training opportunities for students in order to ensure that, upon graduation, students are well-prepared for the working in integrate and/or primary care settings.

\section{PREPARING RESIDENTS AND STUDENTS FOR INTEGRATED CARE}

Residents and students benefit from working together in a clinical setting, in order to understand how integrated care is effective in addressing patients’ multiple health concerns. A number of different approaches exist in order to teach learners the necessary skills of integrated care. Didactic lectures and skills-based training sessions focused on skills, such as knowledge about the various roles and clinical responsibilities of different BHCs is an important first approach for training residents. Behavioral science faculty members can observe residents in 
their interactions with patients and other healthcare providers. Individual or small group discussions and consultations regarding specific patient care concerns can emphasize the utility of behavioral health integration. The implementation of reflecting team activities (e.g., small group observations of patient visits or simulations of patient encounters) encourage learning of collaborative care skills for both BHC students and residents. At Saint Louis University, residents engage in specific integrated care competency activities with MedFT students as part of a rotation.

The cross-training experiences of integrated care from both professions are not without some challenges along the way. For one, time constraints for residents restrict the amount of opportunities for BHC students to shadow them on clinic services. Although residencies may be more open to longitudinal curriculum in order to train residents in the skills of integrated care, dedicated time to practice and develop competence with these skills is not consistently present. MedFT students are generally in the medical sites for only a limited amount of time, which restricts residents' abilities to collaborate with and learn from BHCs. One solution (at Saint Louis University) is that MedFT students deliver brief talks during the lunch hour to medical providers on a variety of services they can offer to patients that fall outside of the traditional anxiety or depression treatment goals (e.g., smoking cessation, parenting skills).

Behavioral health integration in primary and ambulatory care settings may result in improved patient health outcomes. For almost a decade, efforts have been made from both educational and policy sides to foster improved BH services in primary care to address complex medical and mental health issues for underserved patients [24, 25]. This article provides examples of training both medical residents and MedFTs in primary care clinics to care for patients with complex presentations that include medical and mental health concerns. One of the 
goals of training multiple professions of healthcare providers in the same space is to increase their cross-disciplinary communication skills and instill the attitudes and abilities of collaboration. When healthcare trainees learn the integrated care skills and techniques during their supervised clinical experiences, the integrated primary care workforce will be better equipped to address the challenges in chronic medical and mental health issues of vulnerable populations. 


\section{REFERENCES}

1. Patel V, Prince M. Global mental health: a new global health field comes of age. JAMA 2010;303:1976-1977. doi: 10.1001/jama.2010.616

2. Blount A. Integrated primary care: Organizing the evidence. Families Systems and Health 2003;22:121-134. doi: 10.1037/1091-7527.21.2.121

3. Bridges J, Nicholson C, Maben J, Pope C, Flatley M, Wilkinson C, Meyer J, Tziggili M. Capacity for care: meta-ethnography of acute care nurses' experiences of the nurse-patient relationship. $J$ of Adv Nursing 2013;69:760-772.

4. Kodner DL, Spreeuwenberg C. Integrated care: meaning, logic, applications, and implications-a discussion paper. Int J of Int Care 2002;2:1-6. doi: 10.5334/ijic.67

5. Engel GL. The clinical application of the biopsychosocial model. Am J Psychiatry 1980; 137:535-544. doi:10.1093/jmp/6.2.101

6. Engel GL. The need for a new medical model: A challenge for biomedicine. Family Systems Med. 1992;10:317-331.

7. Baird M, Blount A, Brungardt S, Dickinson P, Dietrich A, Epperly T, Green L, Henley D, Kessler R, Korsen N, McDaniel S. Joint principles: Integrating behavioral health care into the patient-centered medical home. Annals of Fam Med 2014;12:183-185. doi: 10.1370/afm.1633

8. Zubatsky M, Harris SM, Mendenhall TJ. Clinical training and practice patterns of medical family therapists: A national survey. Journal of Marital and Family Therapy 2016. doi: 10.1111/jmft.12203

9. Carr A. The effectiveness of family therapy and systemic interventions for child-focused problems. J of Fam Therapy 2009;31:33-45. doi: 10.1111/j.1467-6427.2008.00451.x

10. Katon WJ, Von Korff M, Lin EH, Simon G, Ludman E, Russo J, Ciechanowski P, Walker E, Bush T. The pathways study: A randomized trial of collaborative care in patients with diabetes and depression. Arch of Gen Psych 2004;61:1042-1049. doi:10.1001/archpsyc.61.10.1042

11. Robinson PJ, Reiter JT, editors. Behavioral consultation and primary care: A guide to integrating services. New York, NY: Springer, 2007. doi: 10.1007/978-3-319-13954-8

12. Papadakis S, Cole AG, Reid RD, Coja M, Aitken D, Mullen KA, Gharib M, Pipe AL. Increasing rates of tobacco treatment delivery in primary care practice: Evaluation of the Ottawa model for smoking cessation. Annals of Fam Med 2016;14:235-243. doi: 10.1370/afm.1909

13. Falke SI, D'Arrigo-Patrick E. Medical family therapists in action: Embracing multiple roles. Journal of Marital and Family Therapy 2015;41:428-442. doi: 10.1111/jmft.12104 
14. Thielke S, Vannoy S, Unützer J. Integrating mental health and primary care. Primary Care: Clinics in Office Practice 2007;34(3):572.

15. Peek CJ. Integrated behavioral health and primary care: A common language. In: Talen M, Burke-Valeres A, editors. Integrated Behavioral Health in Primary Care. New York, NY: Springer, 2013:9-31. doi: 10.1007/978-1-4614-6889-9_2

16. Priest HM, Roberts P, Dent H, Blincoe C, Lawton D, Armstrong C. Interprofessional education and working in mental health: In search of the evidence base. Journal of Nursing Management 2008;16:474-485. doi: 10.1111/j.1365-2834.2008.00867.x

17. Prochaska JJ, Nigg CR, Spring B, Velicer WF, Prochaska JO. The benefits and challenges of multiple health behavior change in research and in practice. Prev Med 2010;50:26-29. doi: 10.1016/j.ypmed.2009.11.009

18. Woods LN, Lanza AS, Dyson W, Gordon DM. The role of prevention in promoting continuity of health care in prisoner reentry initiatives. Am J of Pub Health 2013;103:830-838. doi: 10.2105/AJPH.2012.300961

19. Wilson DK. New perspectives on health disparities and obesity interventions in youth. $J$ of Ped Psych 2009;34:231-244. doi: 10.1093/jpepsy/jsn137

20. Zambrana RE, Carter-Pokras O. Role of acculturation research in advancing science and practice in reducing health care disparities among Latinos. Am J of Pub Health 2010;100:18-23. doi: 10.2105/AJPH.2008.138826

21. Hodgson J, Lamson A, Mendenhall T, Tyndall L. Introduction to medical family therapy: Advanced applications. In: Hodgson J, Lamson A, Mendenhall T, Crane DR, editors. Medical family therapy: Advanced applications. New York, NY: Springer, 2014:1-9. doi: 10.1007/978-3319-03482-9_1

22. Tyndall L, Hodgson J, Lamson A, White M, Knight S. Medical family therapy: Charting a course in competencies. Contemporary Family Therapy 2012;34:171-186. doi: 10.1007/s10591012-9191-9

23. McDaniel SH, Doherty WJ, Hepworth J, editors. Medical family therapy and integrated care. Washington, D.C: American Psychological Association, 2014.

24. Manderscheid R, Kathol R. Fostering sustainable, integrated medical and behavioral health services in medical settings. Ann Intern Med 2014;160:61-65. doi: 10.7326/M13-1693

25. Vogel M, Malcore S, Illes R, Kirkpatrick H. Integrated primary care: Why you should care and how to get started. Journal of Mental Health Counseling 2014;36:130-144. doi: 10.17744/mehc.36.2.5312041n10767k51 


\section{Appendix A. Mental Health Integration Case Study}

In the Medical Family Therapy program at Saint Louis University, students serve as behavioral health consultants (BHCs) in primary care. One of the primary care sites where students rotate is at a Federally Qualified Health Center, serving an underrepresented population in metro St. Louis. The BHC at this site operates in Primary Care Behavioral Health (PCBH) model, where briefer consultations with patients and families are delivered and treatment plans are coordinated continually with other providers. Often, the BHC will serve as a coach to patients regarding specific lifestyle habits, as well as an advocate, helping the patient to access resources the family may need that exist outside of the clinic.

During one of the BHCs shifts, a family medicine resident approached her for a case consultation regarding a patient with several co-morbid conditions and financial struggles affording her medications. The patient, $\mathrm{M}$, was an African American male in his late forties, a smoker, very high BMI, had high blood pressure and diabetes. Due to the resident's time constraints, the BHC was to see the patient in order to gain a broader picture of what was going on with $\mathrm{M}$. The BHC reviewed the patient's file, consulted with the doctor on what specific assessments were needed, and was given a warm handoff in the room.

The BHC met with the patient for roughly twenty minutes. The beginning of the session was spent listening to M's story and learning about his job, family, and home life. He talked of his struggles with his weight, inconsistencies in medication adherence, and motivations to quit smoking. Additionally, the BHC assessed for social support, which M stated his wife was his main social contact. The BHC also asked about M's coping skills, and his primary form of coping was relying on his spiritual beliefs. She then used Motivational Interviewing to determine M's readiness to change in regards to quitting smoking. She found that $\mathrm{M}$ was indeed ready to 
quit smoking and motivated to make the necessary life changes. The remainder of the session was spent going over medication management, smoking cessation, and the utilization of his spirituality and social support in order to aid in this process.

At the end of the consultation, the BHC received M's approval to discuss their session with his doctor in order to create an appropriate treatment plan. Upon consulting with the doctor, it was decided that $\mathrm{M}$ would schedule a follow-up appointment for two weeks to check-in with the doctor and care team. In the meantime, the BHC helped coordinate a community resource list for $\mathrm{M}$ and his family members. This list included places where the patient could shop to buy healthier food options to manage weight and blood sugars. Additionally, the care team was able to establish an in-home session with a social worker to help organize M's house so that items and rooms could be assessed easier. 
Table 1. Demographics and Physical Diagnoses seen by MedFTs in Practice (n=334)

$\begin{array}{lll}\text { Variable } & \mathrm{N} & \text { \% } \\ & & \\ & & \\ \text { Gender } & & (26.1) \\ \text { Male } & 87 & (73.9) \\ \text { Female } & 247 & \\ \text { Race } & & (74.3 \%) \\ \text { Caucasian } & 248 & (21.6 \%) \\ \text { African American } & 72 & (2.1 \%) \\ \text { Asian American } & 7 & (2.1 \%) \\ \text { Other } & 7 & \\ \text { Income Level } & & (14.1 \%) \\ \text { Lowest SES } & 47 & (17.7 \%) \\ \text { Lower-Middle SES } & 59 & (27.8 \%) \\ \text { Upper Middle SES } & 93 & (39.8 \%) \\ \text { Highest SES } & 133 & (0.6 \%) \\ \text { Unknown } & 2 & \\ \text { Physical Comorbidities with Depression } & & (25.2 \%) \\ \text { Obesity } & 84 & (18.9 \%) \\ \text { Arthritis } & 63 & (17.4 \%) \\ \text { Musculoskeletal Pain } & 58 & (15.6 \%) \\ \text { Back Pain } & (15.9 \%) \\ \text { Hypertension } & (14.4 \%) \\ \text { Hyperlipidemia } & 52 & (9.9 \%) \\ \text { Headache } & 53 \%) \\ \text { Vascular Disease } & & (6.7 \%) \\ \text { Neuropathy } & & \\ \text { Diabetes } & 53 & \end{array}$


$\underline{\text { Table 2. Residents' Responses to Integrated Care }(\mathbf{n}=18)}$

Referred at Least One Patient to In-house BHCs $\quad 78 \%$

Received follow-up communication about the mental health treatment

$72 \%$

During treatment, the patient made

Minimal to Moderate improvements

$30 \%$

During treatment, the patient made

Moderate to Significant Improvements

$35 \%$

During treatment, the patient had worsening

symptoms or new mental health concerns

$0 \%$ 